\title{
Intensification of turbulent heat transfer in a circular tube by inserting different configuration of finned converging-diverging nozzles turbulators
}

\author{
Zahraa K.Ali ${ }^{\dagger}$, Khudheyer S. Mushatet
}

†ech. Eng. Dep. University of Thi-Qar, Iraq

Mech. Eng. Dep. University of Thi-Qar, Iraq

\begin{abstract}
In this paper, an experimental study has been conducted to show the influence of insertion converge-diverge conical turbulators fitted with rectangular fins inside a circular test tube on Nusselt number, the friction and the overall performance. The air is utilized as working fluid for Reynolds number varied 10000 to 50000. In this investigation, two improvement devices of turbulent heat transfer are utilized. One is the nozzle conical used as turbulators and fixed in the circular tube with three different values of pitch ratio (P.R=1, 1.5 and 2) and the another is rectangular fins placed at the inner surface of the conical turbulators. The conical turbulators fitted with rectangular fins are tested at pitch ratio P.R=1.0 with three different area ratios of the rectangular fins $A r=0.064,0.106$ and 0.149. The experimental results appeared that the heat transfers by using combined the conical nozzle turbulators and the rectangular fins is enhanced by about $234 \%$ for the largest area ratio $(\mathrm{Ar}=0.149)$. Also, the optimal thermal performance is obtained to be larger as compared with plain tube case and the conical turbulators alone.
\end{abstract}

Keywords: Heater transfer augmentation, Conical turbulators, Rectangular fins.

\section{Introduction}

In the last 50 years, the conventional energy sources have been minimizing at a worrying rate and it makes future possible development for power use very hard. Thus, the utilize of the enhancement techniques has become widespread to rise the heat duty for a given size heat exchanger or to decrease the cost and size of heat exchanger. This target can be accomplished in two enhancement techniques: active and passive techniques. The active enhancement techniques is less popular because it needs the addition of external energy to cause a desirable flow modification. On the other hand side, a passive enhancement techniques do not needs stimulation by the external energy and included surface alteration of heat transfer or devices incorporation whose presence results in a modification of flow field. The most popular devices is the conical turbulators, circular rings, fins or ribs insert and swirling flow devices all of these working as the improvement devices [1]. Many researchers studied the problems of the improvement techniques experimentally and theoretically. Zdaniuk et al. [1] described the impacts of helically-finned tubes on heat transfer coefficients and pressure losses for eight tubes fitted with helically fins with one smooth tube. The effects of different helix angles, various fin numbers and fin height to diameter ratios for these tubes were tested in a range of Reynolds number from 12000 to 60000 . The results stated that the maximum value of Nusselt number was obtained by utilizing the eighth tube compared with the other tubes. El- Sayed et al. [2] examined experimentally Nusselt number and pressure drop characteristics in a circular tube integrated with internal longitudinal fins that are interrupted fins and continuous fins. The interrupted fins were fixed inside the flow wise direction into two diverse arrangements: inline manner and staggered manner. At the periodic fully developed region, it was found that the pressure losses for continuous fins were higher than that in an inline arrangement and less than that in a staggered arrangement. Webb et al [3] made an examinations on seven tubes with helically ribs for single phase flow. The helically ribs were mounted in the internal tube surface with several helix angle, various rib numbers and different rib heights in a range of Prandtl numbers from 5.08 to 6.29 . For all tested tubes, the heat transfer improved either by separation of flow at the ribs for tubes having high helix angle (rough tubes) or by a significant increase of surface area for tubes having small helix angle (internally finned tubes). Experimental investigations were represented by Muthusamy et al. [4] to verify the impacts of the conical turbulator with an internal fins in a tube on Nusselt number, thermal performance and pressure losses. The study was done by utilizing two various arrangements, converging turbulator and diverging conical tabulators and with three various pitch ratios. It was noticed that the diverge conical turbulator arrangement for the smallest pitch ratio can assist to improve the heat transfer by about $315 \%$ over that of plain tube. Parmar et al. [5] carried out the experimental analysis to verify the influence of inwardly finned tubes in a laminar flow on turbulent heat transfer intensification. Two types of the internal fins: rectangular and cylindrical fins were inserted at the internal tube periphery at the same hydraulic diameter. The results showed that the maximum rate of heat transfer was obtained for rectangular fins. Experimental investigations were conducted by Durmus [6] to exhibit the impacts of the turbulators inserted into heat exchanger tube at a stable external temperature on the rate of heat transfer. The outer surface was heated by the saturated water vapor while the 
air was flow inside the test tube. The experiments were conducted for eight (8) conical turbulators were fixed at equal distances into the internal pipe with utilize four diverse conical angles for four kinds of turbulators during a range of Reynolds number from $15000_{\text {_ }} 60000$. It was appeared that thermal performance was enhanced by using the conical turbulators with increasing the pressure losses when located in the direct flow area. Kongkaitpaiboon et al. [7] investigated the influences of perforated rings fitted inside a test pipe on heat transfer improvement. The punctured conical ring turbulators were locate in diverge arrangements with various perforated hole numbers and different pitch ratios for various values of Reynolds number. The results showed that the smallest pitch ratio and largest holes number gives the larger thermal performance is around 0.92 at an identical pumping. Eiamsa and Promvonge [8] tested experimentally the characteristics of heat transfer and pressure loss in a plain tube fitted with $\mathrm{V}$ nozzle turbulators with three diverse pitch ratio. The Reynolds number was changed from $8,000-18,000$. The results observed that the maximum enhancement efficiency of about 1.19 is obtained at minimum pitch ratio of $\mathrm{V}$ - nozzle turbulators. Promvonge and Eiamsa [9] utilized experimentally converge and diverge conical nozzle arrays fitted in a circular tube at three pitch ratios for a range of Reynolds number from 8000 to 18000 . The gained results were demonstrated that the the diverging conical tabulators for minimum pitch ratio lead to the larger rate of heat transfer than other arrangement. Anvari et al. [10] also described the effect of conical ring arrangements (diverge conical and converge conical) fitted in a horizontal tube on the heat transfer. The experiments were conducted in the transient flow regime. It is detected that the diverge conical ring arrangement has better Nusselt number by up to $521 \%$ than the converge conical ring arrangement. Experimental examination were testified by Rahul et al [11] to portray the enhancement efficiency and the friction characteristics for inserted conical spring in a heated tube. These conical springs were placed in three different arrangements: converge conical, diverge-conical and converge - diverge conical. It was found that the enhancement efficiency of diverge conical spring arrangement is the largest compared to the other arrangements. Experimental study were expressed by Eiamsa and Promvonge [12] to show the impacts of the diamond conical turbulators on the thermal performance characteristics in a heated tube. The diamond conical turbulators were placed in tandem arrangement with three various cone angles and three different ratios of tail length. It was noted that Nusselt number and pressure losses tends to increase with an increasing of the cone angles and decreases with reducing in the tail length ratio. Experimental examinations were reported by Gowrisankar et al.[13] to display the influences for insertion diverging conical in a tube on the intensification of heat transfer with three various flow rates and pitch ratios. The Reynolds number were ranged from 9382 to 16921 . It was found that the greatest heat transfer rate occur at diverging conical turbulators insertion for the smallest pitch ratio as compared with twisted tapes insertion at same pitch ratio.
Promvonge [14] made an experimental examination to study the impact for conical rings insertion into a test tube on the actual performance and pressure loss. The conical rings were fixed in three different arrangements: converge conical, converge - diverge and diverge conical turbulators with three various diameter ratios to the tube diameter. It was noticed that the rate of heat transfer is greatest for diverge conical rings arrangement by $237 \%$ than other arrangements. Keklikcioglu et al.[15] studied studied numerically the effects of the conical turbulators fitted inside a plane tube on the characteristics of heat transfer and friction for the turbulant flow by using ANSYS CFX program. The conical nozzles were fixed inside a tube with three different values of step numbers and pitch ratios for Reynolds number varied of 6000 to 22000. The results proved that the maximum overall improvement is $11 \%$ for step and spacing ratios equal to 4 and 2 and Reynolds number equal to 6000. Promvonge and Eiamsa [16] tested the actual thermal performance inside a circular tube by using the conical turbulators and snail with three different values from pitch ratios for scope of Reynolds number was (8000-18000). The obtained results proved that the utilizing of the conical turbulators and the snail can assist to augmented the heat transfer as compared with the plain tube by about $316 \%$ at minimum pitch ratio.

In the present work, an experimental study has been carried out to display the combined influence for the conical turbulators and rectangular fins on heat transfer improvement and pressure drop properties in tube under a heat flux as shown in Figure 1. The CD conical turbulators are used with three diverse value of pitch ratios (pitch ratio $=$ pitch $/$ hydraulic diameter $=1.0,1.5$ and 2.0 respectively), while the conical turbulators with the rectangular fins was tested at the smallest pitch ratio $(\mathrm{PR}=1.0)$. This experiments are performed with utilized the air as a working fluid for Reynolds numbers ranged between 10000 to 50000 .

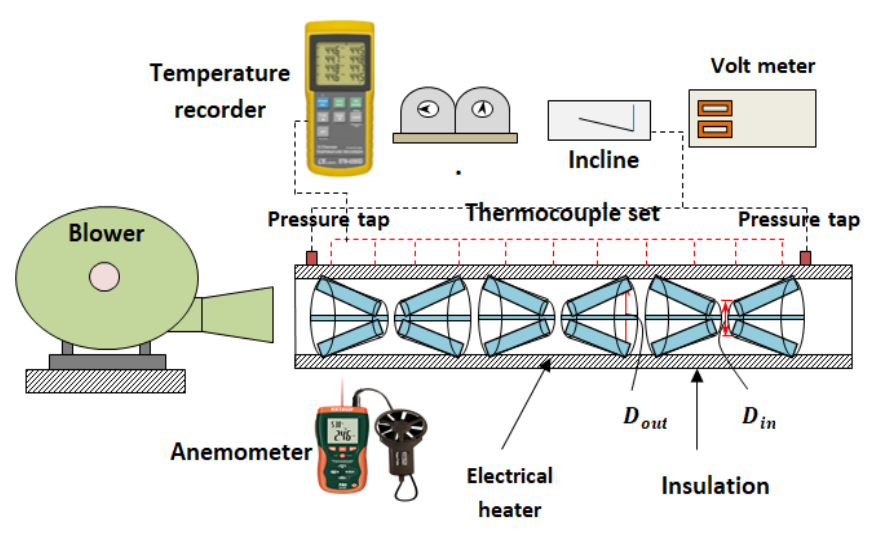

Fig. 1. The schematic diagram of the experimental device. 

different configuration of finned converging-diverging nozzles turbulators

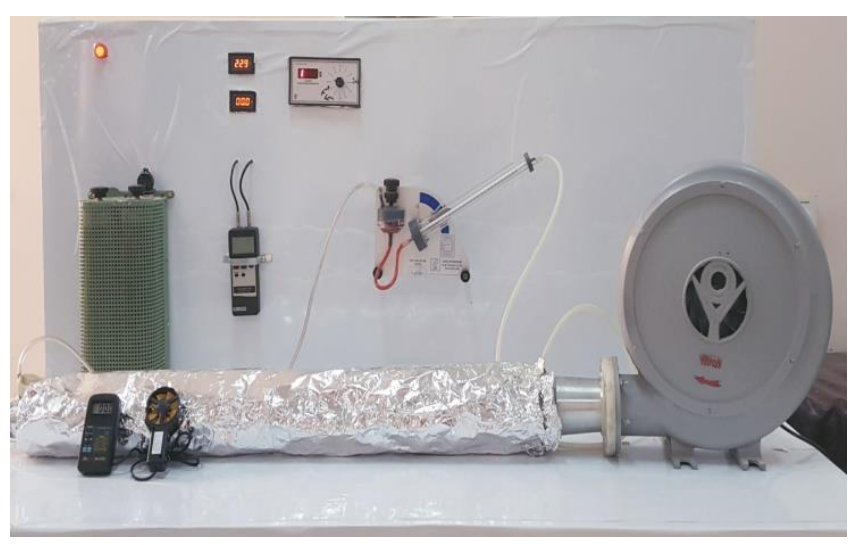

Fig. 2. The photograph view of the test rig.

\section{Experimental set up}

The experiment was conducted in an open experimental loop as illustated in figure (1) and figure (2). The experimental loop consisting of $1.1 \mathrm{~kW}$ blower, the anemometer is utilized to measurement the velocity of an air entry inside a test section. It includes an aluminum tube having $1200 \mathrm{~mm}$ length, $65 \mathrm{~mm}$ external diameter, $60 \mathrm{~mm}$ internal diameter and a thickness of $2.5 \mathrm{~mm}$. To achieve an uniform heat flux, the tube was heated by the electric wire continuously rolling around the tube. An electrical output power was managed from a variac transformer to achieve constant heat flux over the entire length of the tube. An external surface for a test tube was completely insulated to reduce the convective heat losses to the exterior surroundings. The temperature estimations were obtained by utilizing a digital temperature recorder connected to ten thermocouples installed on a local wall of the plain tube to measure the tube wall temperature. While the air bulk temperature was evaluated by utilizing two thermocouple located at an inlet and outlet surface of the test tube section. In general the experimental work rig was an acceptable cost, but there were some difficulties in manufacturing the conical turbulators.

Fig.1 shows the circular pipe with the converge diverge conical nozzle turbulators inserted with the rectangular fins. The conical turbulators was fabricated from the aluminum with $(1=60 \mathrm{~mm})$ in length, cone ends diameters $(\mathrm{d}=30 \mathrm{~mm}$ and $\mathrm{D}=60 \mathrm{~mm}), 1.5 \mathrm{~mm}$ thickness and pitch length equal to $60 \mathrm{~mm}$. The conical turbulators were arranged into a heate tube with three different pitch ratios are 1.0,1.5 and 2.0 respectively.

In addition, the rectangular fins were manufactured from aluminum metal with length $60 \mathrm{~mm}$ and thickness $1 \mathrm{~mm}$. It was made by cutting an aluminum piece by a cutting machine to obtain the required shapes. Four internal fins are fixed inside each of the converge diverge conical turbulators utilizing Spot-welding and arranged on the quarters with equal distance to each other at fixed length $60 \mathrm{~mm}$ with three various area ratios $(\mathrm{Ar}=$ A fin/A cone of $0.064,0.106$ and 0.149 ) for three height $3 \mathrm{~mm}, 5 \mathrm{~mm}$ and $7 \mathrm{~mm}$ respectively to test the impact of area ratio on the thermal performance and pressure losses.
Table 1 shows the geometrical parameter details for the considered problem.

Table. 1. Geometrical parameters for the considered problem.

\begin{tabular}{|c|c|}
\hline \multicolumn{2}{|c|}{ Test tube section } \\
\hline Parameter & Value \\
\hline Length & $1200 \mathrm{~mm}$ \\
\hline Inner diameter & $60 \mathrm{~mm}$ \\
\hline Outer diameter & $65 \mathrm{~mm}$ \\
\hline Material & Aluminum \\
\hline Reynolds number & $10000-50000$ \\
\hline Thickness & $2.5 \mathrm{~mm}$ \\
\hline Fluid & Air \\
\hline \multicolumn{2}{|c|}{ Rectangular fins } \\
\hline Parameter & Values \\
\hline Fin length & $60 \mathrm{~mm}$ \\
\hline Fin height & $3 \mathrm{~mm}, 5 \mathrm{~mm}$ and $7 \mathrm{~mm}$ \\
\hline Number of fins & 4 \\
\hline Material & Aluminum \\
\hline Area ratio & $0.064,0.106$ and 0.149 \\
\hline Thickness & $1 \mathrm{~mm}$ \\
\hline
\end{tabular}

\section{Boundary Conditions}

The following boundary conditions were utilized for each zone of the computational domain to complete the model:

1-The boundary conditions at inlet.

The inlet velocity is uniform.

The flow is isothermal ( $\mathrm{T}=\mathrm{Tin}=298 \mathrm{~K})$.

2 - The boundary condition at wall.

a. On the tube walls and internal fins, the velocity taken to be zero (no slip flow), $\mathrm{u}=\mathrm{v}=\mathrm{w}=0$.

b. The heat flux is constant $(\mathrm{q}=1231 \mathrm{~W} / \mathrm{m} 2)$.

c. $\frac{\partial P}{\partial n}=0$, where $\mathrm{n}$ is a normal unit vector.

d. $k=0$ and $\epsilon=0$.

3- The boundary condition at outet.

a. At outlet, the gage pressure was taken equal to zero atm.

b. Smooth exit for dependent variable $\left(\frac{\partial U}{\partial x}=\frac{\partial V}{\partial x}=\frac{\partial W}{\partial x}=\right.$ 0 )are assumed.

\section{Data reduction}

In the current study, the air is utilized as working fluid that passes into a well insulated tube under uniform heat flux. The rate of heat transferred of air (Qair) is written as:

Qair=Qconv

Where :

$\mathrm{Q}$ air $=\mathrm{m} \mathrm{C} \mathrm{p}(\mathrm{To}-\mathrm{Ti})=$ V.I

A convection heat transfer during a test tube section can be expressed;

$\mathrm{Q} c o n v=h A\left(\bar{T} w-T_{b}\right)$

Where:

$\mathrm{T}_{\mathrm{b}}=\left(\mathrm{T}_{\mathrm{o}}+\mathrm{T}_{\mathrm{i}}\right) / 2$

$\mathrm{T}_{\mathrm{w}}=\sum \mathrm{Twi} / \mathrm{n}$ 
Where $\mathrm{n}$ is number of thermal sensors.

A average Nusselt number, $(\mathrm{Nu})$ can be represented by the following relation:

$N u=\bar{h} . D h / k$

The Reynold number is give from the following relation:

$R e=U . D h / v$

The friction factor is calculated as:

$\mathrm{f}=2 \Delta \mathrm{P}(\mathrm{Dh} / \mathrm{L}) / \rho \mathrm{U}^{2}$

where:

$\mathrm{U}$ is the average of the air velocity in a test tube.

All of the air thermo physical properties are organized at a whole bulk temperature.

The overall thermal performance factor is given by:

$\eta=\left(N_{u w} / N_{u p}\right) /\left(f_{\mathrm{w}} / f_{\mathrm{p}}\right)^{1 / 3}$

\section{Results and discussion}

In this part, the acquired results of the heat transfer and flow characteristics : (Nusselt number, friction index and the overall performance factor) are documented for various values of pitch ratios of the conical nozzle turbulators with various values from area ratios for the coverage - diverge conical turbulators integrated with rectangular fins.

\subsection{Validation}

The experimental results of a plain tube are validated with the known empirical correlations for Dituss - Boeltter and Blassius [17].

$N u=0.023 \operatorname{Re}^{0.8} \operatorname{Pr}^{0.4}$

$f=0.316 / R e^{0.25}$

The validations includes the variation in the mean Nusselt number and flow factors versus Reynolds number as presented in Fig 3. And Fig .4. The average deviation among the results is about $6.4 \%$ and $10 \%$ respectively. This deviation between the results is attributed to the surrounding conditions of the test rig.

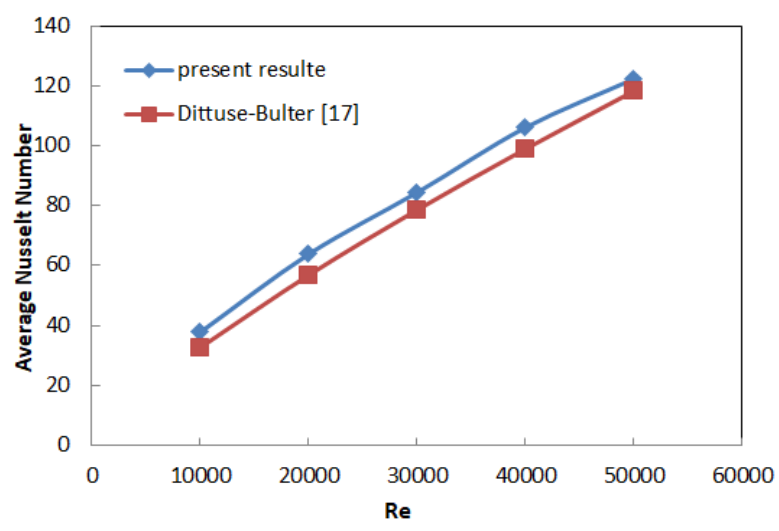

Fig .3. Validation of the present study of average Nusselt number of a plain tube versus Dittus and Boltters correlations.

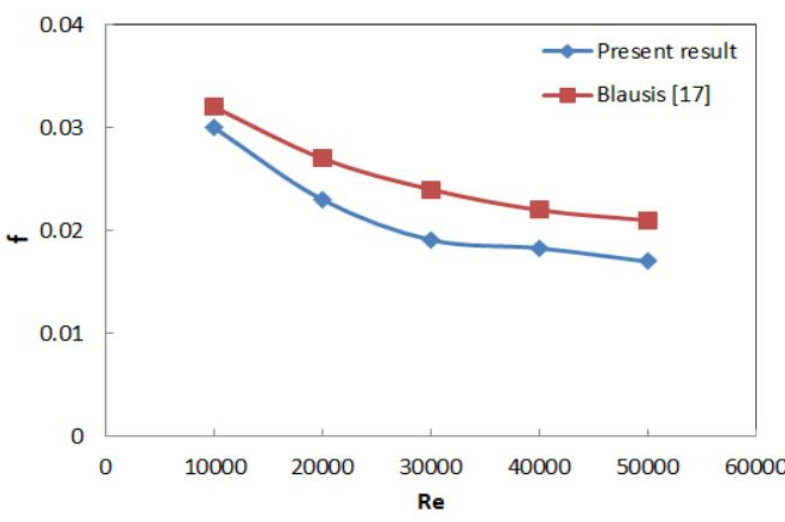

Fig .4. Validation of the present study of friction factor for plain tube versus Blasius corralations.

\subsection{Influence of pitch ratios on Nusselt number $(\mathrm{Nu})$ and the friction factor (f) for CTW $F$}

The variation for a mean Nusselt number with different values of Reynolds number for utilizing $C D$ conical turbulators are observed in Figure (5). It can be appeared that the Nusselt number increase with rising Reynolds number and pitch ratios decreases. As noticed, that the mean Nusselt number from using the conical turbulators is larger than that from utilizing the plain tube for the same conditions. Generally, All the converge-diverge conical turbulators generates high turbulence because it make a secondary flow near the tube wall lead to the dissipation of thermal boundary layer. The conical turbulators are used as a means for heat transfer improvement through the test tube by producing a superior mixing between the core region and the wall surface area. The gained results verified that the Nusselt number $(\mathrm{Nu})$ of using the conical turbulators for pitch ratios $\mathrm{P} . \mathrm{R}=1.0,1.5$ and 2.0 respectively, is improved by $188 \%, 182 \%$ and $176 \%$ respectively.

Figure 6 illustrates the difference between the friction index and Reynolds number for three diverse values of pitch ratio. From this figure, it is noted that the friction index reduces with increasing Reynolds number. Also, the friction with effects of conical turbulators are greater than the empty tube and the minimum pitch ratio ( $\mathrm{P} . \mathrm{R}=1.0)$ results in a larger friction factor. This increase in the friction index as pitch ratios decreasing because of greater tangential contact between wall surface of tube and the secondary flow. 


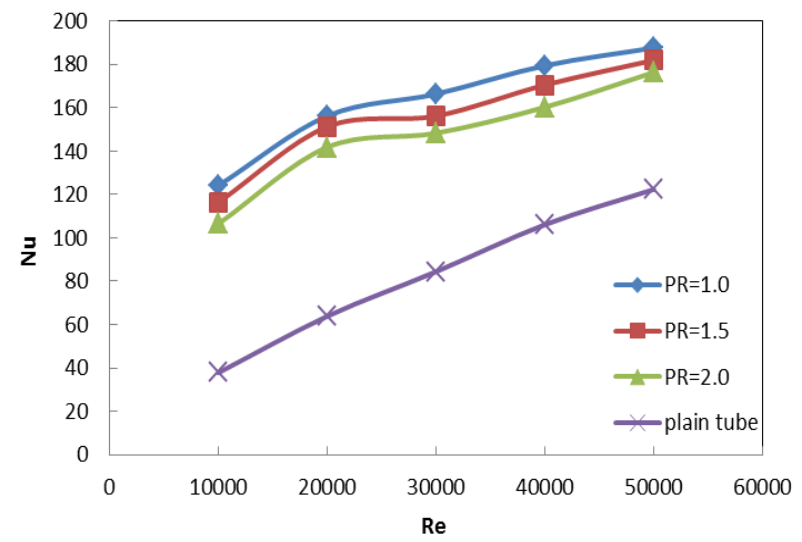

Fig .5. Effect for pitch ratios on average Nusselt numbers $(\mathrm{Nu})$ variation with Reynolds number of CD conical turbulators without internal fins CTW F.

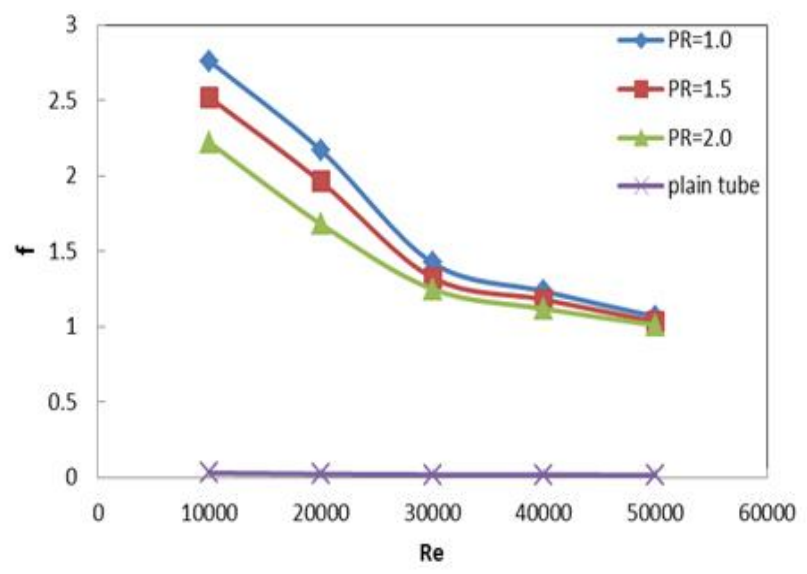

Fig .6. Effect for pitch ratios on the friction factor (f) variation with Reynolds number of CD conical turbulators without internal fins CTW F.

\subsection{Influence of pitch ratio on the overall thermal performance factors for $\mathrm{CTW} F$}

The effect of utilizing the converge-diverge conical turbulator on overall performance factor $(\mu)$ is noted in figure 7 . It is noticed that the overall performance factor decrease with the rising in Reynolds number values and it is also seen that the conical turbulators with the minimum pitch ratio provide the largest overall thermal performance factor. This is due to that the increase in Nusselt number values is higher than the rising in the friction index at higher Reynold numbers with all pitch ratios. It is proved that the higher overall performance factor $(\mu)$ of 0.73 is achieved into a test tube fitted with $\mathrm{CD}$ turbulators at the smallest pitch ratio $\mathrm{PR}=1.0$ and the minimum Reynolds number ( $\mathrm{Re}$ ) for all cases.

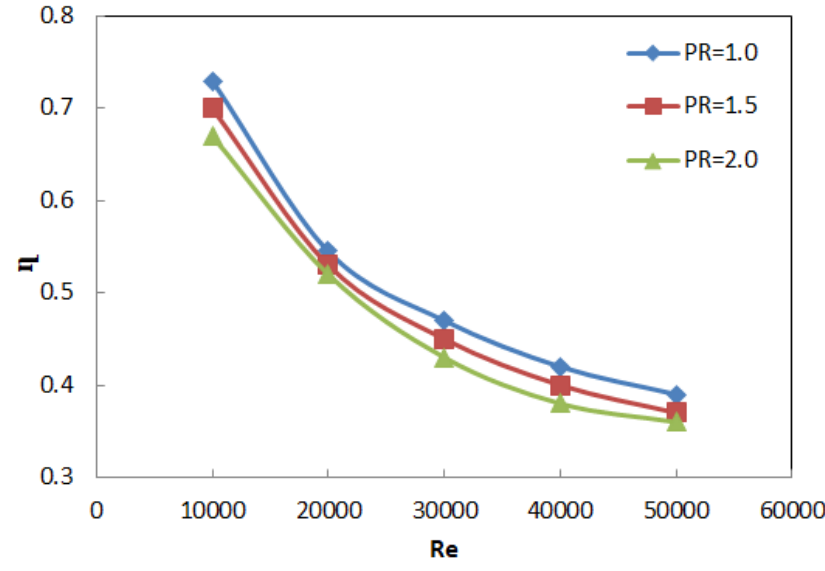

Fig. 7. Effect of pitch ratios on overall thermal performance factor variation with Reynolds number values of conical turbulators without fins CTW F.

\subsection{Influence of fin size on Nusselt numbers and friction facto of CTR $F$}

The impact of using the converge-diverge conical turbulator in common with the rectangular fins on Nusselt number $(\mathrm{Nu})$ is demonstrated in figure 8. It is detected that Nusselt number increase with Reynolds number intensifies. Also as area ratios increase Nusselt number $\mathrm{Nu})$ rise for all the studied cases. The two devices ( conical turbulators and the rectangular fins) gives a considerable increase in heat transfer compared with the empty tube. In addition, the presence of a rectangular fins leads to significant enhancement of heat transported as compared with the conical turbulators alone. This rise in the convective heat transfer is due to that the conical turbulators are used to generate a secondary flow near the tube wall leading to destruction of the thermal boundary layer in addition to the high turbulence resulting from the presence for the rectangular fins that gives an increase in an accelerated flow between the wall of test tube and core regions and long time of flow residence and hence improve the tangential and radial turbulent fluctuations in the tube section.

The variation between the friction index and Reynolds number for different values of fin size is described in Fig. 9. It appears that the friction index reduces with increase in Reynolds number. Also the largest area ratio leads to highest friction factor as compared with the other area ratios. The friction factor with combined effects of $\mathrm{CD}$ conical turbulators and the internal rectangular fins is higher than the plain tube and from the insertion of $\mathrm{CD}$ turbulators alone. The rise in the friction index is because the presence of fins that gives high flow disturbance at CD turbulators entrance and the dissipation of air dynamic pressure due to large viscosity losses at the tube wall surface. Also, the flow friction can occur at the contact between the pressure forces and inertial forces through the thermal boundary layer. The obtained results appeared that the friction index of the turbulators fitted with rectangular fins are greater than the CD conical turbulators alone by around $21 \%$ for area ratio equal to 0.149 . 


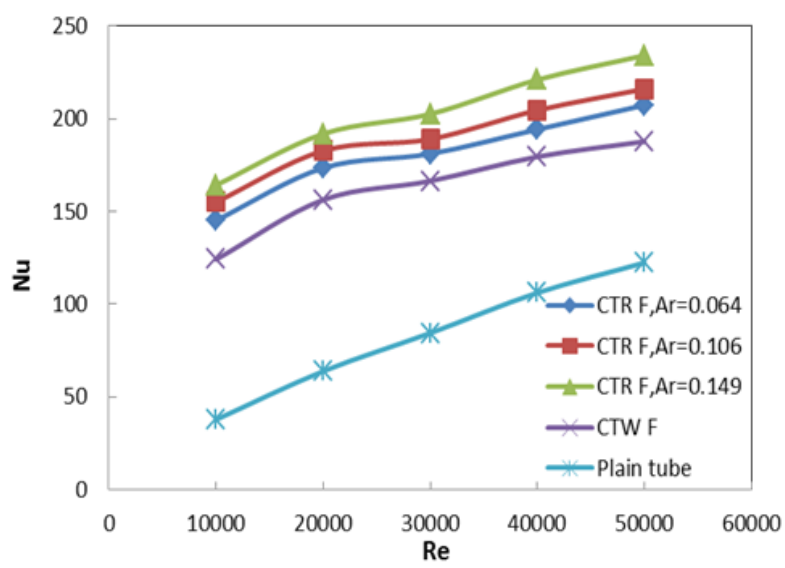

Fig. 8. Influence of fin size on Nusselt number for conical turbulators with fins CTR F at PR=1.0.

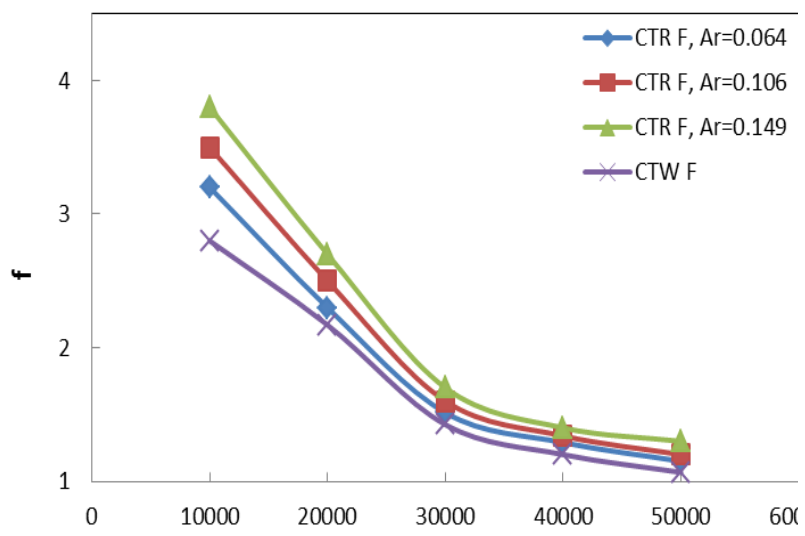

Fig. 9. Influence of fin size on friction factor for conical turbulators with fins $\mathrm{CTR} F$ at $\mathrm{PR}=1.0$.

\subsection{Influence of fin size on the overall thermal performance factor for CTR $\mathbf{F}$}

Fig. 10. displays the variation between the overall thermal performance factor and Reynold numbers for insert conical turbulators fitted with the rectangular fins in a heated tube. It is observed that the overall thermal performance decreases with increasing Reynolds number and it is also noted that the turbulators with the largest area ratio provide the maximum overall thermal performance factor. Over the results, it is found that the use of the rectangular fins provides considerable enhancement of turbulent heat transfer with increase friction factor. The acquired results of the overall thermal performance factor for the introduce the combined conical nozzle turbulators with the rectangular fins are higher than those for the conical only around $14 \%$ for P.R=I.0 and Ar=0.149 due to rise the turbulence intensity generated by fins.

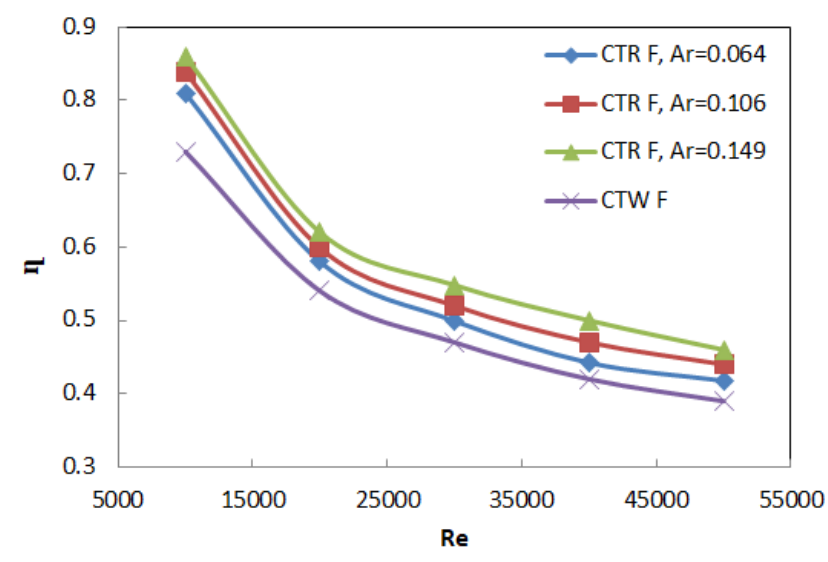

Fig.10. Influence of fin size on the overall thermal performance factor for conical turbulators with fins CTR F at $\mathrm{PR}=1.0$.

\section{Conclusion}

The heat transfer enhancement in a circular tube by using the converge - diverge conical turbulators fitted with the rectangular fins has been experimentally investigated .In this part, the conclusions contains the following.

1. The heat transfer rate in a circular tube can be increased greatly by introducing the conical turbulators with rectangular fins.

2. The conical nozzle turbulators with or without internal fins could be inserted into the test tube for heat transfer improvement.

3. The rectangular fins inserted into a tube fitted with converge-diverge conical turbulators are presented larger heat transfer rates by $19 \%$ as contrasted with those of the tube fitted with the conical turbulators alone and by $59 \%$ as compared with the plain tube for pitch ratio $\mathrm{P} . \mathrm{R}=1.0$ and the largest area ratio $\mathrm{Ar}=0.149$.

4. The Friction factor for the rectangular fins inserted in the conical turbulators is much bigger than the conical turbulators insert alone and the plain tube.

5. Over the range examined, the optimum enhancement efficiency of $434 \%$ is found by utilize of the conical turbulators with rectangular fins at area ratio $\mathrm{Ar}=0.149$ and pitch ratio $\mathrm{P} . \mathrm{R}=1.0$.

6. The highest overall thermal performance of 0.86 is found for using the conical turbulators with the rectangular fins for the largest area ratio $\mathrm{Ar}=0.149$ and pitch ratio P.R $=1.0$.

\section{NOMENCLATURE}

As $\quad$ surface area of the plain tube $\left(\mathrm{m}^{2}\right)$

$\mathrm{Ar}$ area ratio (Afin/Acone)

Afin/Acone area of fin to area of cone

CD converge-diverge conical-nozzle turbulators

CTW F conical turbulators without fin

CTR F conical turbulators fitted with rectangular fins

$\mathrm{C}_{\mathrm{p}} \quad$ specific heat capacity $(\mathrm{J} / \mathrm{Kg} \mathrm{K})$

$\mathrm{D}_{\mathrm{i}} \quad$ inner diameter of the plain tube $(\mathrm{m})$

$\mathrm{D}_{\mathrm{o}} \quad$ outer diameter of the plain tube (m)

f friction factor

$\mathrm{f}_{\mathrm{w}} \quad$ friction factor with turbulators 
$\mathrm{f}_{\mathrm{p}} \quad$ friction factor of the plain tube

$\mathrm{h} \quad$ mean heat transfer coefficient $\left(\mathrm{W} / \mathrm{m}^{2} \mathrm{k}\right)$

$\mathrm{k}$ thermal conductivity (W/m K)

1 the distance between conical nozzles ( $\mathrm{m}$ )

$\mathrm{L} \quad$ the length of plain tube ( $\mathrm{m})$

$\mathrm{Nu} \quad$ Nusselt number

$\mathrm{N}_{\mathrm{uw}} \quad$ Nusselt number with turbulators

$\mathrm{N}_{\text {up }} \quad$ Nusselt number of plain tube

$\Delta \mathrm{P} \quad$ pressure drop (pa)

P.R pitch ratio for the conical- turbulator

Q the rate of heat transfer ( W)

Re Reynolds number

$\mathrm{T}_{\mathrm{w}} \quad$ wall temperature $\left(\mathrm{C}^{0}\right)$

$\mathrm{T}_{\mathrm{b}} \quad$ bulk temperature $\left(\mathrm{C}^{0}\right)$

$\mathrm{U}$ mean velocity $(\mathrm{m} / \mathrm{s})$

Greek symbols

v kinematics viscosity $\left(\mathrm{m}^{2} / \mathrm{s}\right)$

$\eta \quad$ thermal performance factor

$\rho \quad$ fluid density $\left(\mathrm{kg} / \mathrm{m}^{3}\right)$

\section{References}

[1] Gregory J. Zdaniuk, Louay M. Chamra and Pedro J. Mago, Experimental determination of heat transfer and friction in helically-finned tubes, Experimental Thermal and Fluid Science 32 (2008)761-775.

[2] Saad A. El-Sayed, Sayed A. El-Sayed, Mohamed E. Abdel-Hamid and Mohamed M. Sadoun, Experimental Study of Turbulent Flow Inside a Circular Tube with Longitudinal Interrupted Fins in the Stream wise Direction, Experimental Thermal and Fluid Science, (1997)1-15.

[3] Webb, R. L., R. Narayanamurthy, and P. Thors, Heat transfer and friction characteristics of internal helical-rib roughness. Journal of Heat Transfer 122.1 (2000): 134142 .

[4] Muthusamy, M. Vivar, I. Skryabin , K. Srithar, Effect of conical cut-out turbulators with internal fins in a circular tube on heat transfer and friction factor. International Communications in Heat and Mass Transfer 44 (2013): 64-68.

[5] K.S.Parmar, M.J.Patel and Umang R. Soni, Heat Transfer Enhancement Using Internal Fins of same Hydraulic Diameter, International Journal on Recent and Innovation Trends in Computing and Communication, vol 2,2014,pp.2321-8169.

[6] Aydin Durmus, Heat transfer and exergy loss in cut out conical turbulators, Energy Conversion and Management 45(2004) 785-796.

[7] V. Kongkaitpaiboon, K. Nanan, S. Eiamsa-ard ,Experimental investigation of heat transfer and turbulent flow friction in a tube fitted with perforated conical-rings, International Communications in Heat and Mass Transfer,vol37,(2010),pp.560-567.

[8] S. Eiamsa-ard and P. Promvonge, Experimental investigation of heat transfer and friction characteristics in a circular tube fitted with V-nozzle turbulators, International Communications in Heat and Mass Transfer, vol 33,(2006),pp. 591-600.

[9] Pongjet Promvonge and Smith Eiamsa-ard, "Heat transfer and turbulent flow friction in a circular tube fitted with conical-nozzle turbulators, International Communications in Heat and Mass Transfer 34 (2007) 7282.

[10] A.R. Anvari, R. Lotfi, A.M. Rashidi, S. Sattari, Experimental research on heat transfer of water in tubes with conical ring inserts in transient regime, International Communications in Heat and Mass Transfer, vol 38,(2011),pp.668-671.

[11] Rahul M. Gupta, Bhushan C. Bissa, heat transfer enhancement and friction factor analysis in tube using conical spring insert ,International Jornal or Research ,vol 4,may 2015,pp.253-260.

[12] Smith Eiamsa-ard, Pongjet Promvonge, Thermal characterization of turbulent tube flows over diamondshaped elements in tandem, International Journal of Thermal Sciences ,vol 49 ,(2010) ,pp.1051-1062.

[13] K. Gowrisankar, P. S .KishoreK, Augmentation Heat transfer in a circular tube using divergent nozzle as Insert, International Journal for Research in Applied Science \& Engineering Technology, vol 3, 2015,pp. 2321-9653.

[14] P. Promvonge, Heat transfer behaviors in round tube with conical ring inserts, Energy Conversion and Management, vol 49, (2008),pp. 8-15.

[15] Orhan Keklikcioglu, Toygun Dagdevir, Veysel Ozceyhan, A CFD based thermo-hydraulic performance analysis in a tube fitted with stepped conical nozzle turbulators, Journal of Thermal Engineering Accepted, vol 2,2016, pp. 913-920.

[16] P. Promvonge and S. Eiamsa-ard, Heat transfer enhancement in a tube with combined conical-nozzle inserts and swirl generator, Energy Conversion and Management 47 (2006) 2867-2882.

[17] Incopera F.P. , Dewitt D.P., Introduction to heat transfer, Fourth Edition,ISBN:0-471-38649-9. 